\title{
SCIDoc

\section{Elimination The HIV From The Human Body Using Acoustics Nano-Waves}

Hafdaoui $\mathrm{H}^{*}$

Faculty of Technology, Electronics Department, University of Batna 2, Algeria.

\section{Abstract}

In this paper i suggest a new method to eliminate the HI Virus from the human body, by acoustics nano-waves and send it through the human body. My idea is that the patient must be lying naked on a table and the surface of table contains acoustic nano-waves generators and between the table and the patient we need to put coupling gel ; which is medium that helps the waves to move from the first medium (generators) to a second medium (human body) and as reminder it works the same as the (ultrasound) but with a very high frequency when generate the waves it propagate in the whole human body and every time the waves meet with the HI Virus it breakthrough and destroy it[6]. Our work is interested in the elimination of this disease.

Keywords: Acoustics Nano-Waves; HIV; Eliminate the HI Virus.

\section{Introduction}

Tens of millions of people have been infected by the human immunodeficiency virus (HIV) since it was first recognized in the early 1980s, and more than 20 million have died from ensuing disease [1].

Human Immunodeficiency Virus (HIV) is the virus that causes Acquired Immune Deficiency Syndrome (AIDS). Infection with HIV can weaken the immune system in human body to a level at which it has difficulty fighting off certain infections [2].

The membrane of the virus HIV consists of glycoproteins (Gp120 - Gp41) which give to the virus its full function, Structure and function of an HIV gp120 and gp41 is well explained in [3-5]. and ravage the glycoproteins (Gp120 -Gp41) on the HIV's membrane using acoustic nono-waves well explained in [6].

The development of nanotechnology in the field of medicine can save a lot of human lives . this work is basicly based on applying nanotechnology (acoustics nano-waves) in the field of medicine and exactly the aids in which i propose a device that generates acoustics nano-waves with a high frequency that reaches to $2 \mathrm{THz}$ .We are not interested in the frequency of the waves in the human body but also the great importance is generating these waves where we need about $0,5 \mathrm{Thz}$ to $2 \mathrm{Thz}$ and there is no effect no harm to the human body by this nano-waves.

\section{Proposing The Device}

The device is a table it's whole surface contains acoustic nanowaves generating cells (figure1). The waves frequency is between 0.5 and $2 \mathrm{THz}$ to get the waves length between 2 and $6 \mathrm{~nm}$ (figure2) for the sake of ravaging the glycoproteins on the HIV's membrane [1], because when destroying those proteins the virus loses it's full function (Figure3) .

\section{Principle Function of the Device}

We put the coupling gel all over the surface of the table then the patient lay naked on it, where as his body must touch the surface of the table, after starting the device (generating acoustics nanowaves) those waves will spread from the generating medium to the patient's body. Keeping in mind the coupling gel is a medium that helps in spreading the waves from the generators to the human body.

After the spreading of the waves in the patient body and every time it meets with the virus (HIV) it ravages the glycoproteins

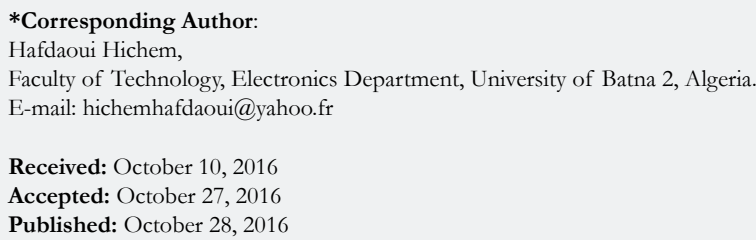

Copyright: Hafdaoui $\mathbf{H}^{\circ}$ 2016. This is an open-access article distributed under the terms of the Creative Commons Attribution License, which permits unrestricted use, distribution and reproduction in any medium, provided the original author and source are credited. 
Figure 1. Surface of the Table.

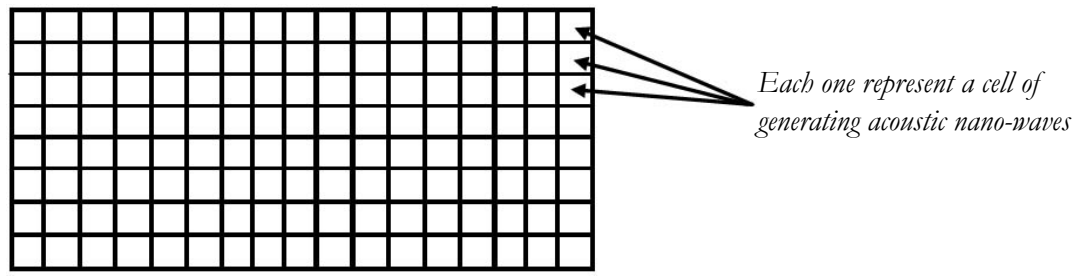

Figure 2. The Frequency Versus Length of the Wave.

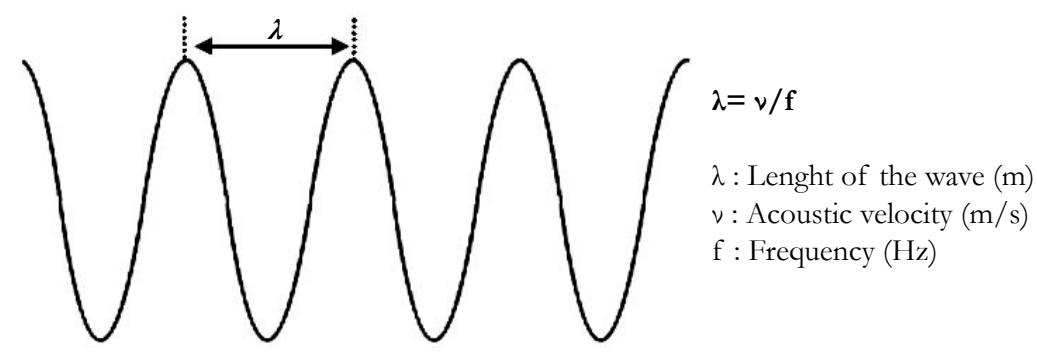

Figure 3. A-HIV Active , B- HIV Non-Active.
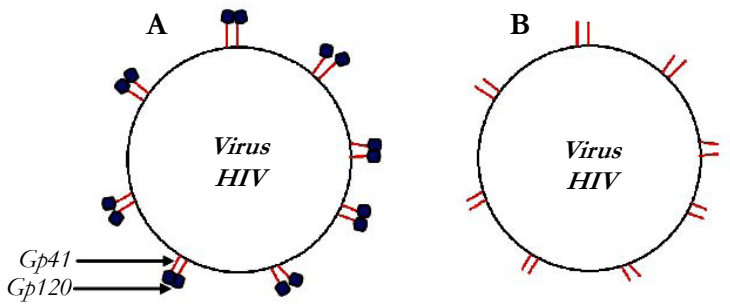

Figure 4. Proposed Method [6].

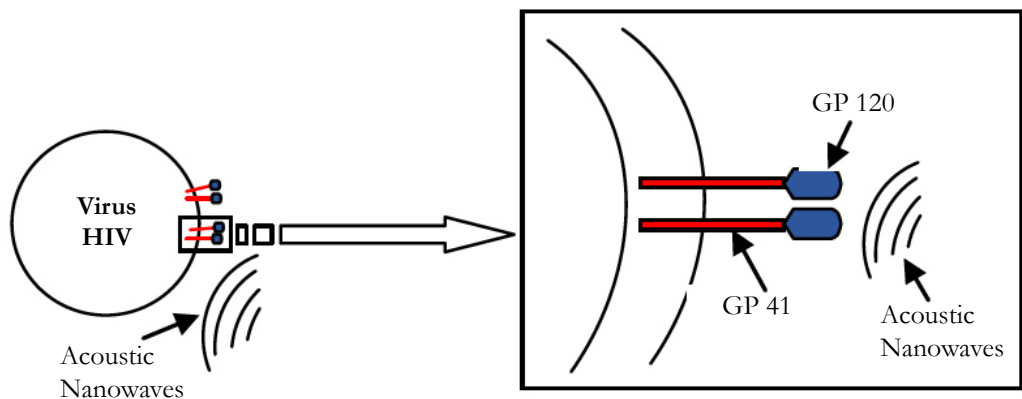

(Gp41,Gp120) on the membrane of this dangerous virus (Figure4).

\section{Expected Results}

We know that the the glycoproteins (Gp41,Gp120) gives to the HIV it's full function. When we destroy those proteins the virus became non-functional and the activity of the virus in the human body will be stopped.

\section{Conclusion}

This work is just a Theoretical idea we can enter with it to the realistic applications. it's success makes the HIV Virus one of the simplest illnesses and we can cure it easily and the most positive thing in this cure there is no side effects in the human body like the one produced by the pharmaceutical drugs.

\section{References}

[1]. Robert F. Stengel (2005) Mutation and Control of the Human Immunodeficiency Virus , 13th Yale Workshop on Adaptive and Learning systems, Yale University, New Haven, CT.

[2]. Hyungbo Shim, Seung-Ju Han, Chung Choo Chung, Sang Won Nam, Jin Heon Seo (2003) Optimal Scheduling of Drug treatment for HIV Infection: Continuous Dose Control and Receding Horizon Control. Int J Control Autom Syst. 1(3): 282 -288

[3]. Kwong PD, Wyatt R, Robinson J, Sweet RW, Sodroski J, et al., (1998) Structure of an HIV gp120 envelope glycoprotein in complex with the CD4 receptor and a neutralizing antibody. Nature. 393: 648-659.

[4]. Marie Pancera, Shahzad Majeed, Yih-En Andrew Ban, Lei Chen, Chih-chin Huang, et al., (2010) Structure of hiv-1 gp120 with gp41-interactive region reveals layered envelope architecture and basis of conformational mobility. Pro Natl Acad Sci. 107(3): 1166-1171.

[5]. David C Chan, Deborah Fass, James M Berger, Peter S Kim (1997) Core Structure of gp 41 from the HIV Envelope Glycoprotein. Cell. 89: 263-273.

[6]. Hafdaoui Hichem (2015) Ravaging The Glycoproteins (Gp120 -Gp41) On The HIV's Membrane Using Acoustic Nonowaves (Theoretical Study). Persian J Med Sci. 2 (4): 93-95. 